\title{
Erratum to "Equivalent Circuit-Based Analysis of CMUT Cell Dynamics in Arrays"
}

H. Kağan Oğuz, Student Member, IEEE, Abdullah Atalar, Fellow, IEEE, and Hayrettin Köymen, Senior Member, IEEE

TN the original publication of the paper [1], the funding source was inadvertently omitted from the footnote on page 1016. The footnote should have read "Manuscript received November 20, 2012; accepted February 14, 2013. This work was supported by the Scientific and Technological Research Council of Turkey (TUBITAK) under project grant 110E216. A. Atalar acknowledges the support of the Turkish Academy of Sciences (TUBA)." The authors regret this omission.

\section{REFERENCES}

[1] H. K. Oğuz, A. Atalar, and H. Köymen, "Equivalent circuit-based analysis of CMUT cell dynamics in arrays," IEEE Trans. Ultrason. Ferroelectr. Freq. Control, vol. 60, no. 5, pp. 1016-1024, 2013.
Manuscript received November 20, 2012; accepted February 14, 2013 This work was supported by the Scientific and Technological Research Council of Turkey (TUBITAK) under project grant 110E216. A. Atalar acknowledges the support of the Turkish Academy of Sciences (TUBA).

The authors are with the Electrical and Electronics Engineering Department, Bilkent University, Ankara, Turkey (e-mail: oguz@ee.bilkent. edu.tr).

DOI http://dx.doi.org/10.1109/TUFFC.2013.2693 